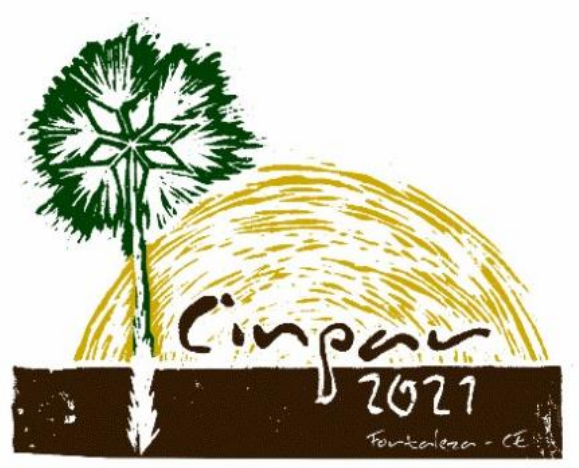

XVII Congresso Internacional sobre Patologia e

Reabilitação das Construções

XVII Congreso Internacional sobre Patología y Rehabilitación de las Construcciones

XVII International Conference on Pathology and Constructions Rehabilitation

FORTALEZA (Brasil), 3 a 5 de junho de 2021

https://doi.org/10.4322/CINPAR.2021.129

\title{
Monitoramento eletroquímico de aço-carbono em argamassas com diferentes tipos de cimento e concentrações de cloretos
}

\section{Electrochemical monitoring of carbon steel in mortars with different types of cement and chloride concentrations}

\author{
Wesley Vítor DANTAS DE CARVALHO BEZERRA ${ }^{1}$, Mohara ALVES DE MEDEIROS ${ }^{1}$, Maria SILVA FREITAS ${ }^{1}$, Ana \\ Luiza NÓBREGA PEREIRA DA SILVA ${ }^{1}$, Gracielle FERREIRA DE SOUZA ${ }^{1}$, Gibson ROCHA MEIRA ${ }^{1,2}$ \\ ${ }^{1}$ Federal University of Paraíba, Campus I - Lot. Cidade Universitária, PB, 58051-900, Brazil, \\ bezerrawesleyvitor@gmail.com,mohara.medeiros@gmail.com,mariasilvajn@gmail.com, \\ ananobrega95@outlook.com,graciellef.souza@hotmail.com \\ ${ }^{2}$ Federal Institute of Education, Science and Technology of Paraíba, Av. Primeiro de Maio, 720 - Jaguaribe, João Pessoa \\ - PB, 58015-435, Brazil, gibsonmeira@yahoo.com
}

\begin{abstract}
Resumo: A corrosão das armaduras é uma das principais fontes de deterioração do concreto armado. Dentre as causas mais comuns, tem-se o ingresso de íons cloreto, elemento comumente presente em ambientes marinhos e suas proximidades. Uma vez na matriz cimentícia, esses íons podem se apresentar na forma de cloretos livres, quimicamente combinados ou fixados fisicamente em estruturas hidratadas. Visto que somente os cloretos livres se movimentam na matriz cimentícia, a fixação de cloretos reduz a velocidade de deslocamento dos íons e, por sua vez, a capacidade de fixação de cloretos depende principalmente da composição da matriz cimentícia. Neste contexto, o presente trabalho tem como objetivo investigar a influência da capacidade de fixação de cloretos de diferentes tipos de cimento Portland na corrosão das armaduras de aço-carbono. Para tanto, armaduras de aço-carbono foram postas em corpos de prova cúbicos de argamassas com diferentes tipos de cimento - com adição de escória de alto forno (CP III), pozolânico (CP IV) e de alta resistência inicial (CP V) - e com diferentes concentrações de cloretos adicionados à mistura ( $0 \%$, $0.15 \%, 0.40 \%, 0.80 \%$ e $1.20 \%$ em relação à massa de cimento). 0 monitoramento das amostras foi executado através de medidas de potencial de circuito aberto e de resistência de polarização linear em idades preliminares (menores que 30 dias) e mais avançadas (aproximadamente 11 meses). Por fim, realizou-se a análise dos resultados, considerando os diferentes tipos de cimento utilizados, e comparou-se os dados obtidos com valores referência da literatura.
\end{abstract}

Palavras-chave: corrosão; cloretos; argamassa; adições minerais.

\begin{abstract}
Reinforcement corrosion is a major source of deterioration in reinforced concrete structures. Among the most common causes, there is the ingress of chloride ions, an element commonly present in and nearby marine environments. Once in the cementitious matrix, these ions can be presented as free chlorides, chemically combined or physically fixed in hydrated structures. Since only the free chlorides move in the cementitious matrix, the chloride fixation reduces the mobility of these ions and, in turn, the chloride fixation capacity depends mainly on the composition of the cementitious matrix. In this context, the present work aims to investigate the influence of the chloride-binding capacity of different types of Portland cement on the corrosion of carbon steel reinforcement. For this purpose, carbon steel reinforcements were placed in
\end{abstract}


cubic mortar specimens with different types of cement - with addition of blast furnace slag (CP III), pozzolanic (CP IV) and high initial strength (CP V) - and with different concentrations of chlorides added to the mixture $(0 \%, 0.15 \%, 0.40 \%, 0.80 \%$ and $1.20 \%$ by weight of cement). The monitoring of the samples was performed through measurements of open circuit potential and linear polarization resistance at preliminary ages (less than 30 days) and at a later period (approximately 11 months). Finally, the results were analyzed, considering the different types of cement used, and the data obtained was compared with reference values from the literature.

Keywords: corrosion; chlorides; mortar; mineral additions.

\section{Introdução}

A corrosão das armaduras é considerada umas das principais causas de deterioração das estruturas de concreto armado (Mehta \& Monteiro, 2006). Segundo Meira (2017), a corrosão no concreto armado é uma problemática que afeta a construção civil de forma global, tendo em vista o volume de casos registrados e a precocidade com que essas reações ocorrem nas estruturas. Os danos causados ao concreto apresentam-se sob a forma de expansão, fissuração e fragmentação do cobrimento, além dos danos estruturais devido à perda da área transversal do aço e da ligação entre a armadura e o concreto (Mehta \& Monteiro, 2006).

Dentre as causas de corrosão das armaduras, a presença dos cloretos no concreto armado é considerada uma das principais. Os íons cloreto podem estar presentes no concreto pelo uso de agregados de antigas regiões marinhas, água contaminada, aditivos aceleradores de pega, ou podem penetrar nas estruturas de concreto pelo contato com água do mar, atmosfera marinha, poluentes industriais e sais de degelo (Ribeiro et al., 2013).

De modo geral, no ataque por cloretos, o início da corrosão ocorre através da ação conjunta dos íons cloreto, das moléculas de água e de oxigênio que penetram nos poros do concreto armado e, ao alcançarem a armadura, causam a ruptura pontual da película passivadora do aço, caracterizando uma corrosão por pites (Figueiredo \& Meira, 2013).

Os métodos utilizados para introdução dos íons cloreto no concreto são variados, podendo os cloretos serem adicionados ao concreto durante sua mistura ou introduzidos em amostras curadas através de diversos mecanismos de transporte (absorção capilar, difusão iônica, permeabilidade e migração iônica).

Segundo Meira (2017), uma vez presentes na matriz cimentícia, os cloretos podem estar na forma de cloretos livres, quimicamente combinados ou fixados fisicamente em estruturas hidratadas. Para cloretos adicionados na mistura do concreto, a capacidade de fixação química e/ou física dos cloretos na matriz cimentícia depende essencialmente do material cimentício e do teor de cloretos totais (Arya et al., 1990). Sabendo-se que os cloretos livres são os que se movem no concreto e que podem posteriormente desencadear um processo corrosivo no aço, os concretos que possuem a capacidade de fixar altos teores de cloretos podem proporcionar uma maior proteção com relação à corrosão da armadura.

Diante do cenário exposto, o presente trabalho apresenta uma análise de parâmetros eletroquímicos (potencial de circuito aberto e densidade de corrente de corrosão) de barras de aço-carbono inseridas em argamassas cimentícias, com diferentes tipos de cimento e variados teores de cloretos (adicionados à mistura).

\section{Materiais e métodos}

\subsection{Materiais}

Para produzir as argamassas, foram utilizados três diferentes tipos de cimento: cimento Portland com adição de escória de alto forno (CP III), cimento Portland pozolânico (CP IV) e cimento Portland de alta resistência inicial (CP V). Esses foram escolhidos por representarem extremos quanto à composição química dos cimentos comercialmente disponíveis no Brasil. 
O agregado miúdo utilizado foi uma areia média de rio. Suas propriedades físicas estão apresentadas no Quadro 1 e na Figura 1, as quais apresentam resultados satisfatórios para uso em concretos segundo os requisitos da norma NBR 7211 (2019).

Quadro 1 - Propriedades físicas da areia

\begin{tabular}{|c|c|}
\hline Areia Média & Resultados \\
\hline Dmáx & $2.36 \mathrm{~mm}$ \\
\hline $\begin{array}{c}\text { Modulo de finura (Obtido após } \\
\text { granulometria NBR 248) }\end{array}$ & 2.54 \\
\hline Massa Unitária (NBR NM 45) & $1.52 \mathrm{~g} / \mathrm{cm}^{3}$ \\
\hline Massa Específica (NBR NM 52) & $2.59 \mathrm{~g} / \mathrm{cm}^{3}$ \\
\hline Torrões de argila (NBR 7218) & $0.99 \%$ \\
\hline Material Pulverulento (NBR NM 46) & $\begin{array}{c}\text { Material passante na peneira 75 } \mu \mathrm{m} \text { não } \\
\text { expressivo (apenas 1.5\%) }\end{array}$ \\
\hline
\end{tabular}

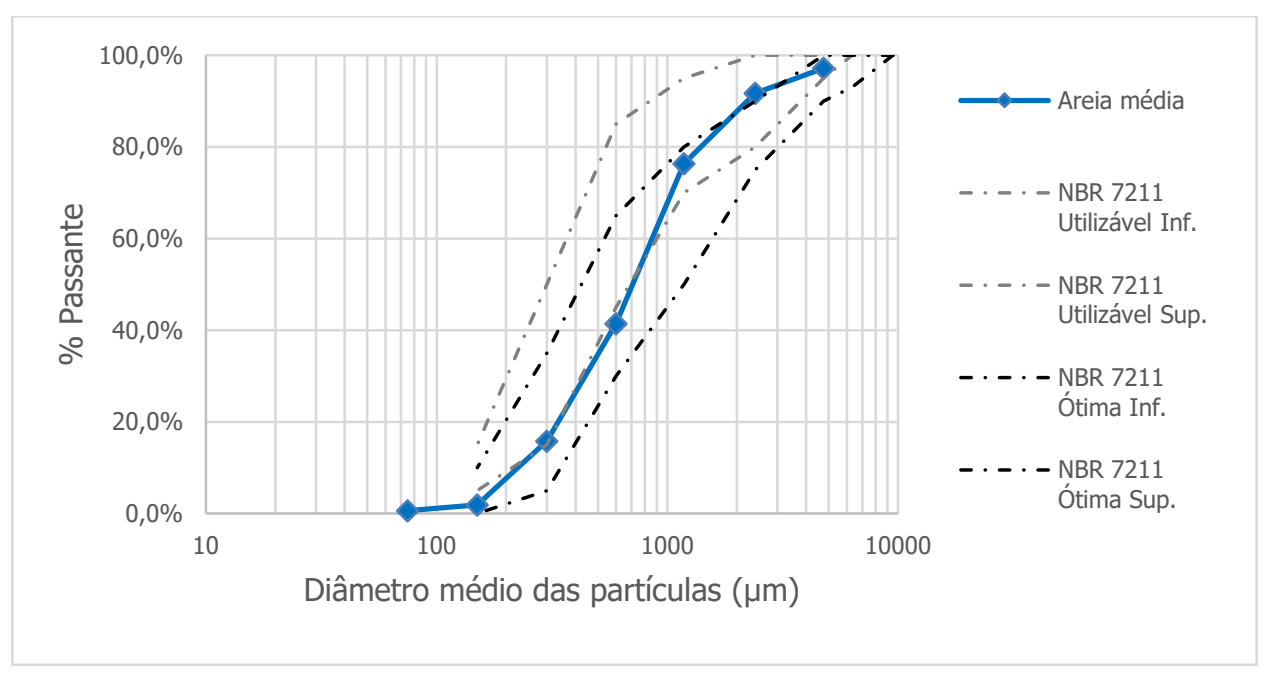

Figura 1 - Granulometria da areia

Utilizou-se água potável comumente fornecida pela Companhia de Água e Esgotos da Paraíba (CAGEPA) para a produção das argamassas, a mesma água utilizada em obras de construções locais.

As armaduras foram barras de aço-carbono, tipo CA-50, nervuradas e com diâmetro nominal de $6.3 \mathrm{~mm}$.

\subsection{Produção dos corpos de prova}

\subsection{1 - Tratamento das barras de aço}

Inicialmente as barras apresentavam produtos de corrosão superficiais decorrentes do contato com ar e umidade ambiente. Como as condições superficiais do aço têm efeito significativo no seu comportamento eletroquímico e na sua resistência à corrosão, as armaduras foram tratadas antes da exposição aos cloretos.

Dessa maneira, foi realizada uma decapagem mecânica inicial utilizando uma escova rotatória de palha de aço. A duração dessa etapa foi até que a superficialmente não fosse notado produtos de corrosão visíveis. Em seguida, as barras passaram por uma limpeza química baseada nas recomendações da ASTM G1-03 (2011). Nesta limpeza, as barras foram lavadas em ácido clorídrico com hexametilenotetramina por uma lavadora ultrassónica durante 15 minutos para remoção de produtos de corrosão residuais. Após isso, as barras foram escovadas manualmente em água corrente durante 2 minutos a fim de remover qualquer vestígio do ácido. Depois, as barras foram imersas em acetona durante 2 minutos para facilitar a remoção da umidade residual nas suas superfícies. Por fim, as barras foram secas com papel toalha e a área de exposição 
do aço foi delimitada nos últimos $3.0 \mathrm{~cm}$ de uma das extremidades. As barras então foram cobertas com resina epóxi e, após 24 horas, com a epóxi endurecida, o procedimento da limpeza química foi repetido. Após isso, as barras foram secas e cobertas com papel filme a fim de impedir o contato com oxigênio e umidade ambiente.

\subsection{2 - Moldagem das amostras}

Foram produzidas diferentes amostras de argamassas variando o tipo de cimento (CP III, CP IV e CP V) e os teores de cloretos adicionados à água de amassamento da mistura $(0 \%, 0.15 \%, 0.40 \%, 0.80 \%$ e $1.20 \%$ em relação à massa de cimento). O sal utilizado nesse estudo foi o cloreto de sódio.

A moldagem foi realizada em moldes cúbicos de dimensões de $8 \times 8 \times 8 \mathrm{~cm}$, sobre uma mesa vibratória. Para cada cubo, duas barras de aço foram posicionadas de forma que o cobrimento mínimo fosse de $2.0 \mathrm{~cm}$. As argamassas foram produzidas com traço 1:2 (cimento:areia) e fator água/cimento de 0.5 , sendo estas proporções iguais para todas as misturas.

Para cada tipo de cimento foram moldadas 10 amostras cúbicas, sendo 2 amostras para cada uma das 5 concentrações de cloretos. Ou seja, no total foram 30 corpos de prova e 60 barras para todas as situações.

A desmoldagem ocorreu 24 horas após a produção das argamassas e a cura foi realizada em uma câmara úmida com umidade relativa $\geq 90 \%$ por um período 7 dias.

\subsection{Monitoramento eletroquímico}

As medidas eletroquímicas obtidas ao longo do monitoramento foram potencial de corrosão medido em circuito aberto $\left(E_{\text {corr }}\right)$ e resistência de polarização linear $\left(R_{p}\right)$ para todas as amostras. Os equipamentos utilizados para obtenção de tais dados foram: um potenciostato de bancada ACM - GillAC com compensação de queda ôhmica, uma Gaiola de Faraday e software específico para aquisição e tratamento dos dados.

\subsection{1 - Potencial de corrosão em circuito aberto}

Para as medidas de potencial de corrosão, foi utilizado como eletrodo de referência o eletrodo de calomelano saturado (SCE) e o contra eletrodo emepregado foi uma chapa de aço inox, conforme mostrado na Figura 2.

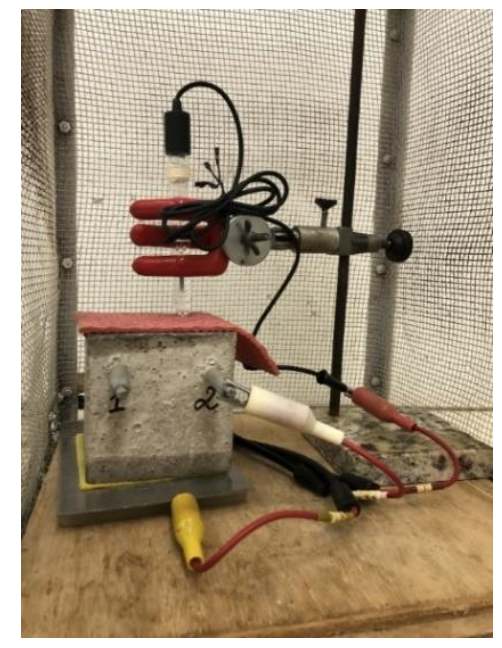

Figura 2 - Arranjo para as medidas eletroquímicas

\subsection{2 - Resistência de polarização linear}

A técnica de resistência de polarização linear é utilizada para determinar a velocidade instantânea da corrente de corrosão na barra de aço. A equação de Stern-Geary (Eq. 1) foi utilizada para obter os valores de corrente de corrosão ( $\left.i_{\text {corr }}\right)$, considerando-se o valor de B igual à $26 \mathrm{mV}$. Por fim, para obter a densidade de 
corrente de corrosão ( $\left.I_{\text {corr }}\right)$ foi utilizado a Eq. 2, que relaciona a corrente de corrosão e a área polarizada da armadura.

$$
i_{\text {corr }}=\left(\frac{B}{R_{p}}\right)
$$

Onde B é uma constante de corrosão $(\mathrm{mV})$; e $R_{p}$ é a resistência de polarização linear $\left(\Omega \cdot \mathrm{cm}^{2}\right)$;

$$
I_{\text {corr }}=\left(\frac{i_{\text {corr }}}{\mathrm{A}}\right)
$$

Onde $i_{c o r r}$ é a corrente de corrosão $(\mu \mathrm{A})$; e A é a área de exposição da armadura $\left(\mathrm{cm}^{2}\right)$.

\section{Resultados e discussões}

\subsection{Potenciais de corrosão em circuito aberto}

As Figuras 3, 4 e 5 mostram os resultados das medidas de potencial de corrosão em circuito aberto das armaduras de aço-carbono embutidas em argamassas de CP III, CP IV, e CP V. Os limites de probabilidade de ocorrência de corrosão ativa em cada gráfico são provenientes da norma ASTM C876 (2015). Como se pode notar, em todas as figuras há uma tendência dos potenciais se deslocarem para valores menos eletronegativos com o tempo. Para interpretar tal situação, é necessário considerar os processos simultâneos que ocorrem nos corpos de prova: a perda de eletrólito durante e após a cura, a formação progressiva da capa passivadora nas barras e a hidratação dos cimentos.
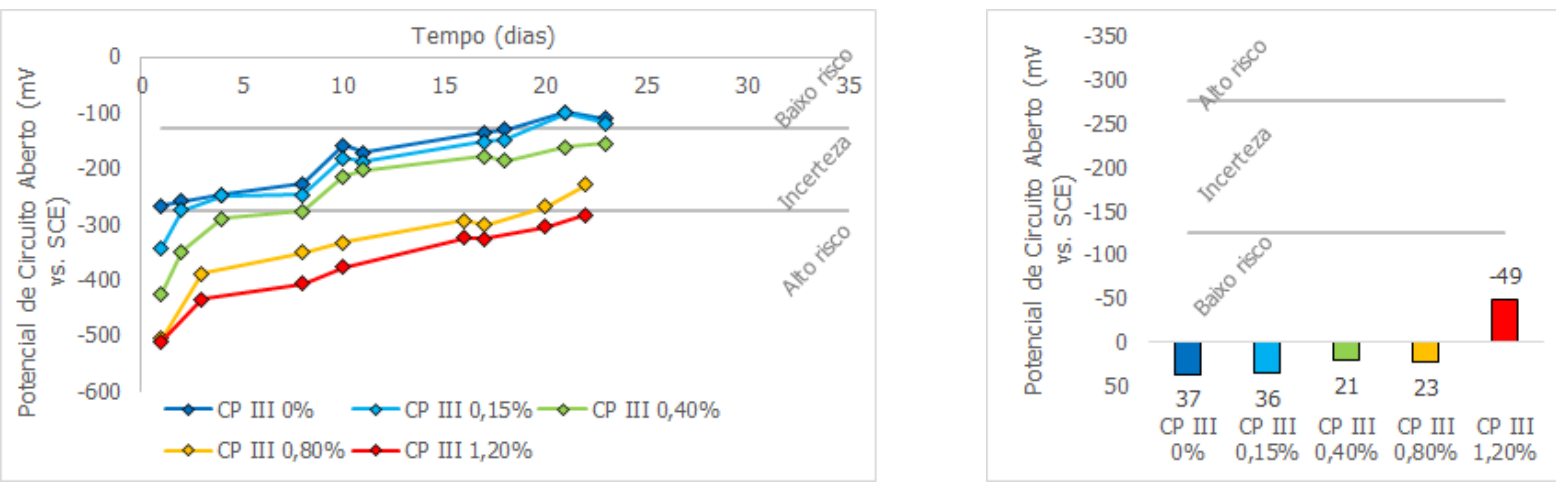

Figura 3 - Potenciais de circuito aberto das argamassas de CP III nas primeiras idades (esquerda) e com idades de $\approx 11$ meses (direita)
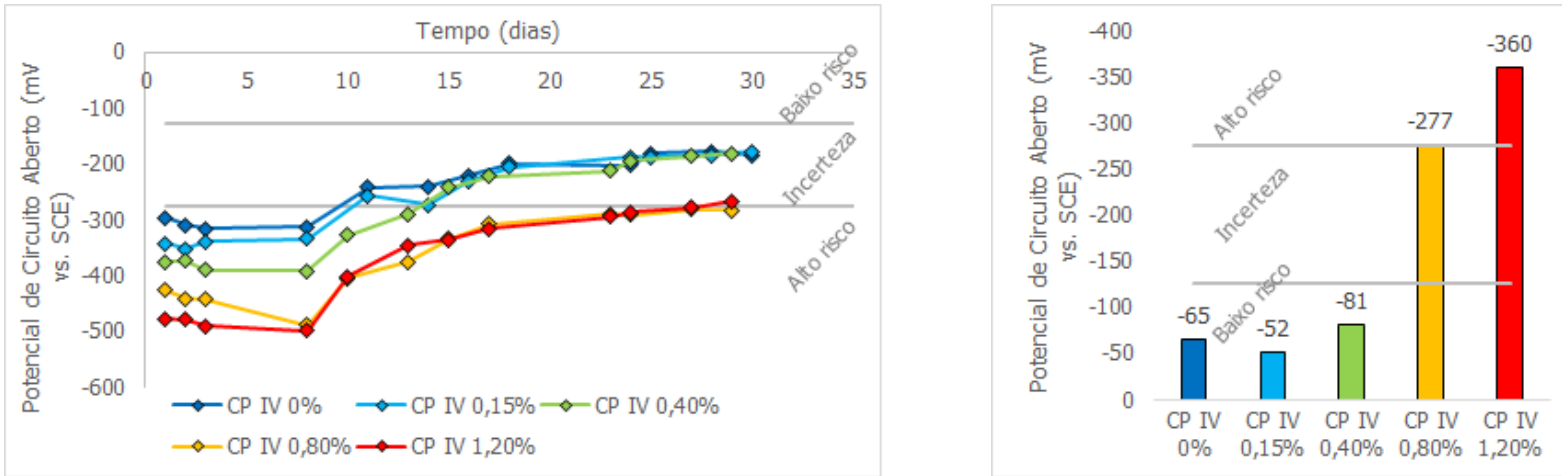

Figura 4 - Potenciais de circuito aberto das argamassas de CP IV nas primeiras idades (esquerda) e com idades de $\approx 11$ meses (direita) 

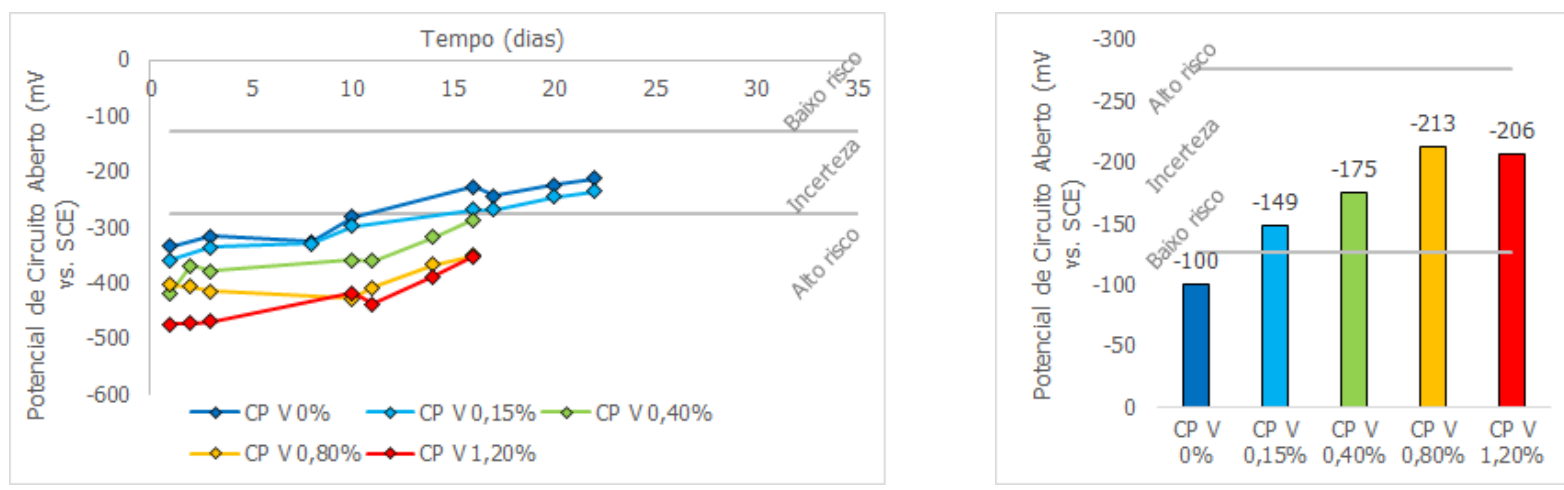

Figura 5 - Potenciais de circuito aberto das argamassas de CP V nas primeiras idades (esquerda) e com idades de $\approx 11$ meses (direita)

Primeiramente, ocorre uma perda de eletrólito nas amostras quando elas são retiradas da cura, pois a umidade relativa ambiente cai de $90 \%$ para condições ambiente de laboratório. Isso dificulta a mobilidade iônica e, consequentemente, a ocorrência das reações de corrosão nas amostras. Segundo Medeiros et al. (2017), maiores teores de umidade tendem a resultar em potenciais de corrosão mais eletronegativos, pois há um aumento na condutividade elétrica do sistema. Entretanto, Michel et al. (2013) afirmam que, tanto para as barras em condição passiva quanto para as barras em corrosão ativa, as variações de temperatura e umidade relativa não influenciam os valores de potencial de corrosão. Essa discrepância pode ser devido às faixas de umidade testadas, com variações maiores (de $95 \%$ para $65-75 \%$ ) no primeiro estudo e menores (entre $75 \%$, $85 \%$ e $96 \%$ ) no segundo estudo.

Adicionalmente, após o tratamento das armaduras, o aço-carbono estava em sua condição pura quando entrou em contato com as argamassas na moldagem, ou seja, desde esse momento houve uma ocorrência gradual de reações de oxidação para formar as capas passivadoras. Essas capas servem como barreiras físicas que mitigam ocorrência de reações de corrosão adicionais, sendo essa mitigação mais ou menos efetiva dependendo da agressividade do ambiente. Entretanto, para formação e estabilização dessas capas é necessário um tempo mais prolongado. No estudo de Koga et al. (2018), amostras levaram até 60 dias para formação da capa passiva, com acréscimo do potencial (valores menos negativos) nos dias seguintes. Ainda nesse estudo, as barras de aço em argamassas com cimento Portland comum levaram pouco mais de 120 dias para estabilizarem seus potenciais de circuito aberto.

Por último, as diferentes composições dos cimentos indicam influência na resistência à corrosão das armaduras. No CP IV há ocorrência de reações pozolânicas que consomem parte da reserva alcalina do cimento. Essas reações reduzem o pH da matriz o que, por sua vez, diminui a resistência à corrosão por cloretos das armaduras. No caso do CP V, não há ocorrência de reações pozolânicas e sua reserva alcalina é constante. Por fim, no caso da escória de alto forno presente no CP III, sua hidratação ocorre independente da presença do hidróxido de cálcio, mas quando em contato com o hidróxido de cálcio e gesso do cimento Portland, essa reação é acelerada (Mehta \& Monteiro, 2006). Nesse estudo, na idade de 11 meses, apenas as amostras de CP IV com $0.8 \%$ e $1.2 \%$ de cloretos apresentaram alta probabilidade de ocorrência de corrosão ativa.

\subsection{Densidade de corrente de corrosão}

As Figuras 6, 7 e 8 apresentam os valores das densidades de corrente das armaduras nas diferentes argamassas ao longo do tempo. Pode-se notar que, no geral, há uma tendência de decréscimo ao longo do tempo dos valores de densidade de corrente. Os valores limites que classificam a intensidade de corrosão nos gráficos são provenientes do estudo de Andrade et al. (2004). Os valores de densidade de corrente obtidos corroboram com os de potencial, pois ambos indicam que, nas primeiras idades, a situação de passivação não foi alcançada e as barras estão em corrosão ativa. Já para a idade de 11 meses, apenas as amostras de CP IV com $0.80 \%$ e $1.20 \%$ de cloretos apresentam taxa de corrosão consideráveis. Para corrosão 
ativa, a umidade influencia a taxa de ocorrência de reações de corrosão (Michel et al., 2013), ou seja, após retirar as amostras da cura, o decréscimo da umidade nas amostras contribuiu para redução da densidade de corrente. Além disso, em conformidade com os resultados dos potenciais de corrosão nas primeiras idades, à medida que a concentração de cloretos nas amostras aumenta, a densidade de corrente também aumenta.
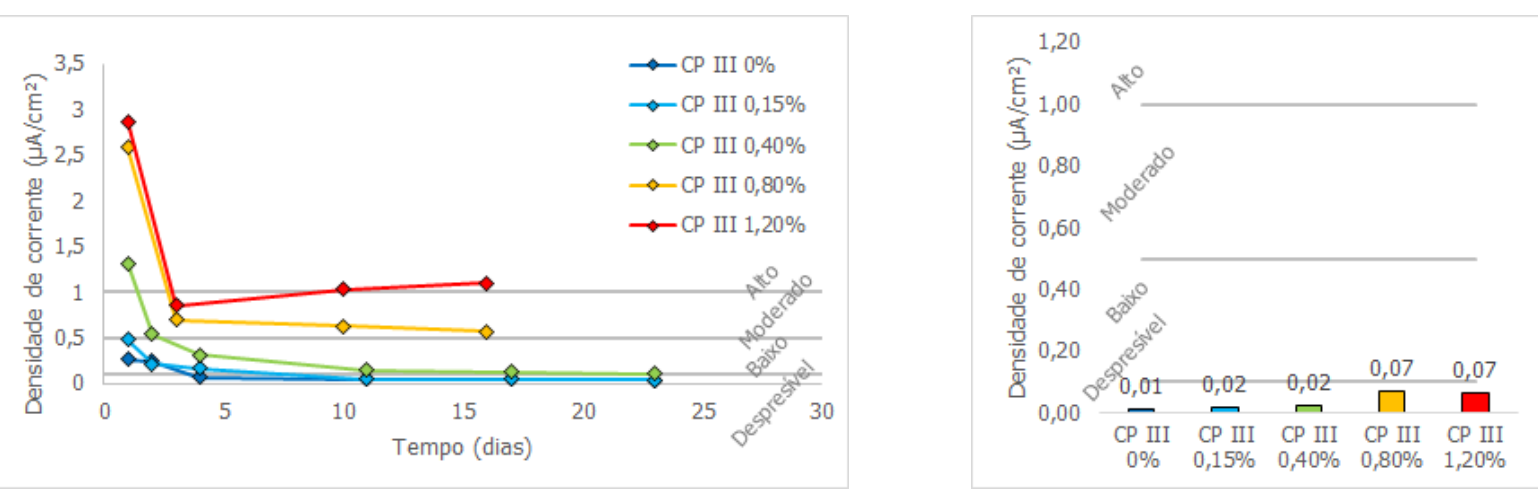

Figura 6 - Densidades de corrente das argamassas de CP III nas primeiras idades (esquerda) e com idades de $\approx 11$ meses (direita)
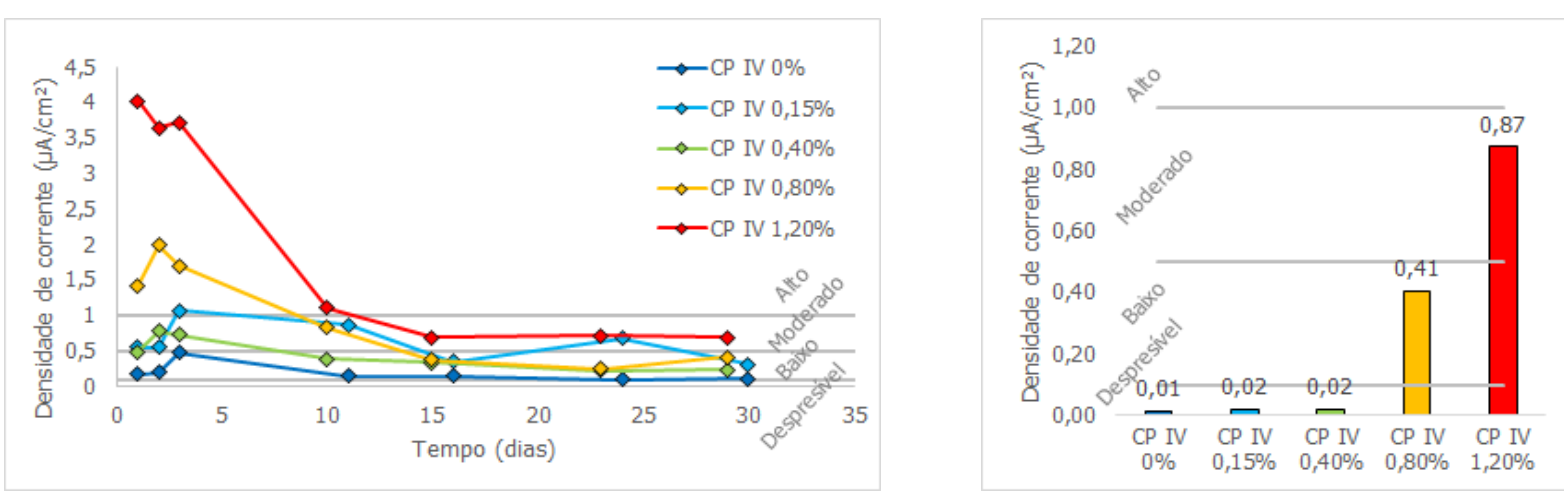

Figura 7 - Densidades de corrente das argamassas de CP IV nas primeiras idades (esquerda) e com idades de $\approx 11$ meses (direita)
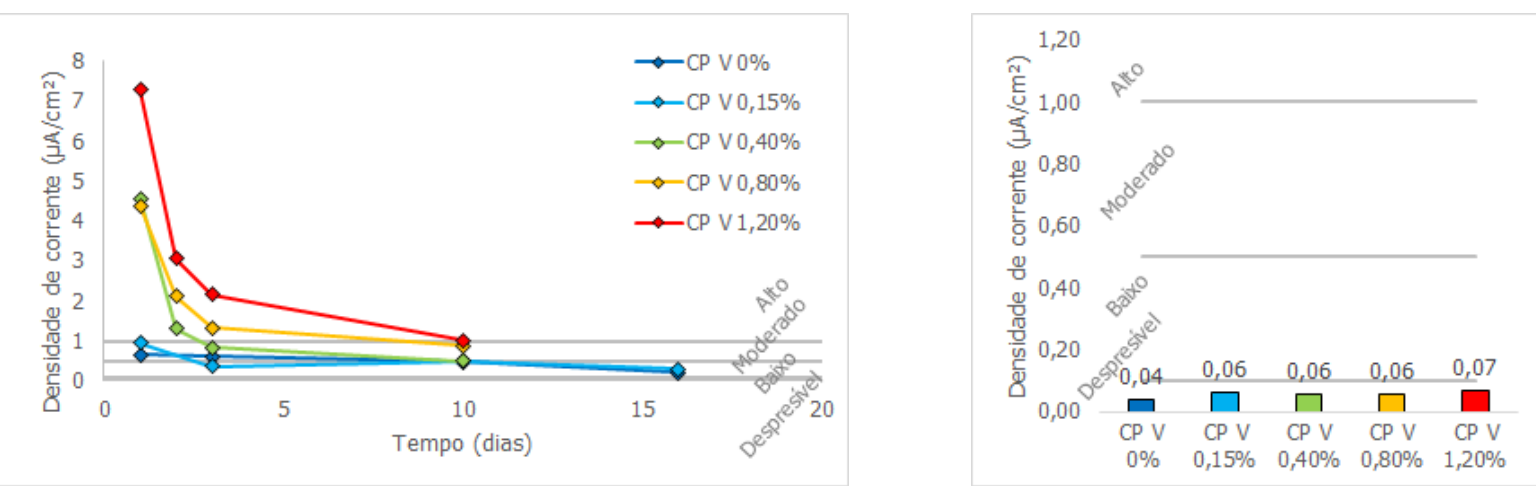

Figura 8 - Densidades de corrente das argamassas de CP V nas primeiras idades (esquerda) e com idades de $\approx 11$ meses (direita)

\section{Conclusões}

Diante do conteúdo exposto no presente trabalho, é possível concluir que:

- Os resultados de potencial de circuito aberto deslocaram-se para valores mais positivos com o passar do tempo, devido principalmente à perda de eletrólito pós cura, a formação progressiva da película de passivação nas barras e a hidratação dos cimentos. Além disso, nas idades preliminares, com o 
aumento da concentração de cloretos adicionados às amostras, tem-se potenciais de circuito aberto mais eletronegativos.

- Em relação aos resultados de densidade de corrente de corrosão, nota-se um decréscimo dos valores ao longo do tempo. Nas idades preliminares, conforme houve o acréscimo das concentrações de cloretos nas argamassas, a densidade de corrente aumentou, em concordância com os resultados dos potenciais de corrosão.

- Por fim, os valores finais de potencial de circuito aberto e de densidade de corrente de corrosão demonstram que apenas as barras do CP IV $0.80 \%$ e $1.20 \%$ não atingiram a situação de passivação e por isso, estão em corrosão ativa. Uma possível explicação é que a redução da alcalinidade pelas reações pozolânicas em conjunto com as altas concentrações de cloretos nessas amostras não permitiram a estabilização das capas passivas.

\section{Agradecimentos}

Os autores são gratos às empresas Mizu Cimentos Especiais e Polimix Concreto pelo fornecimento de um dos cimentos utilizados nesse estudo.

\section{Referências Bibliográficas}

ABNT NBR 7211. (2019). Agregados para concreto - Especificação.

Andrade, C., Alonso, C., Gulikers, J., Polder, R., Cigna, R., Vennesland, Salta, M., Raharinaivo, A., \& Elsener, B. (2004). Recommendations of RILEM TC-154-EMC: "Electrochemical techniques for measuring metallic corrosion" Test methods for on-site corrosion rate measurement of steel reinforcement in concrete by means of the polarization resistance method. Materials and Structures, 37(273), 623-643. https://doi.org/10.1617/13952

Arya, C., Buenfeld, N. R., \& Newman, J. B. (1990). Factors influencing chloride-binding in concrete. Cement and Concrete Research, 20(2), 291-300. https://doi.org/10.1016/0008-8846(90)90083-A

ASTM C876. (2015). Standard Test Method for Corrosion Potentials of Uncoated Reinforcing Steel in Concrete. https://doi.org/10.1520/C0876-15.2

ASTM G1-03. (2011). Standard Practice for Preparing, Cleaning, and Evaluating Corrosion Test Specimens.

Figueiredo, E. P., \& Meira, G. (2013). Corrosión de armadura de estructuras de hormigón. In Boletín Técnico 06.

Koga, G. Y., Albert, B., Roche, V., \& Nogueira, R. P. (2018). A comparative study of mild steel passivation embedded in Belite-Ye'elimite-Ferrite and Porland cement mortars. Electrochimica Acta, 261(January), 66-77. https://doi.org/10.1016/j.electacta.2017.12.128

Medeiros, M. H. F., Rocha, F. C., Medeiros-JUNIOR, R. A., \& Helene, P. (2017). Corrosion potential: influence of moisture, water-cement ratio, chloride content and concrete cover. Revista IBRACON de Estruturas e Materiais, 10(4), 864-885. https://doi.org/10.1590/s1983-41952017000400005

Mehta, P. K., \& Monteiro, P. J. M. (2006). Concrete: Microstructure, Properties, and Materials (3rd ed.). The McGraw-Hill Companies, Inc. https://doi.org/10.1036/0071462899

Meira, G. R. (2017). Corrosão de armaduras em estruturas de concreto: Fundamentos, diagnóstico e prevenção. Editora IFPB.

Michel, A., Nygaard, P. V., \& Geiker, M. R. (2013). Experimental investigation on the short-term impact of temperature and moisture on reinforcement corrosion. Corrosion Science, 72, 26-34. https://doi.org/10.1016/j.corsci.2013.02.006

Ribeiro, D. V., Sales, A., Sousa, C. A. C., Almeida, F. C. R., Cunha, M. P. T., Lourenço, M. Z., \& Helene, P. (2013). Corrosão em Estruturas de Concreto Armado (1st Ed.). Elsevier. 